\title{
Apoptotic activity of 5-fluorouracil in breast cancer cells transformed by low doses of ionizing $\alpha$-particle radiation
}

\author{
RICHARD PONCE-CUSI ${ }^{1}$ and GLORIA M. CALAF ${ }^{1,2}$ \\ ${ }^{1}$ Instituto de Alta Investigación, Universidad de Tarapacá, Arica 8097877, Chile; \\ ${ }^{2}$ Center for Radiological Research, Columbia University Medical Center, New York, NY 10032, USA
}

Received October 2, 2015; Accepted November 6, 2015

DOI: $10.3892 / \mathrm{ijo} .2015 .3298$

\begin{abstract}
Globally, breast cancer in women is the leading cause of cancer death. This fact has generated an interest to obtain insight into breast tumorigenesis and also to develop drugs to control the disease. Ras is a proto-oncogene that is activated as a response to extracellular signals. As a member of the Ras GTPase superfamily, Rho-A is an oncogenic and a critical component of signaling pathways leading to downstream gene regulation. In chemotherapy, apoptosis is the predominant mechanism by which cancer cells die. However, even when the apoptotic machinery remains intact, survival signaling may antagonize the cell death by signals. The aim of this study was to evaluate 5-fluorouracil (5-FU) in cells transformed by low doses of ionizing $\alpha$-particle radiation, in breast cancer cell lines on these genes, as well as apoptotic activity. We used two cell lines from an in vitro experimental breast cancer model. The MCF-10F and Tumor2 cell lines. MCF-10F was exposed to low doses of high linear energy transfer (LET) $\alpha$-particles radiation $(150 \mathrm{keV} / \mu \mathrm{m})$. Tumor2, is a malignant and tumorigenic cell line obtained from Alpha5 (60cGy+E/60cGy+E) injected into the nude mice. Results indicated that 5-FU decreased H-ras, Rho-A, p53, Statl and increased Bax gene expression in Tumor 2 and decreased Rac1, Rho-A, NF- $\kappa$ B and increased Bax and caspase-3 protein expression in Tumor2. 5-FU decreased $H$-ras, $B c l-x L$ and $N F-\kappa B$ and increased $B a x$ gene expression. 5-FU decreased Rac1, Rho-A protein expression and increased Bax and caspase-3 protein expression in MDA-MB-231. Flow cytometry indicated $21.5 \%$ of cell death in the control MCF-10F and $80 \%$ in Tumor2 cell lines. It can be concluded that 5-FU may exert apoptotic activity in breast cancer cells transformed by low doses of ionizing $\alpha$-particles in vitro regulating genes of Ras family and related to apoptosis such as Bax, Bcl-xL and NF- $\kappa \mathrm{B}$ expression.
\end{abstract}

Correspondence to: Dr Gloria M. Calaf, Instituto de Alta Investigación, Universidad de Tarapacá, Calle Antofagasta 1520, Arica 8097877, Chile

E-mail: gmc24@columbia.edu

Key words: 5-FU, H-ras, Rac1, Rho-A, p53, Stat1, caspase-3, $\mathrm{Bcl}-\mathrm{xL}, \mathrm{Bax}, \mathrm{NF}-\kappa \mathrm{B}$, apoptosis, breast cancer cell lines

\section{Introduction}

Globally, breast cancer in women is the leading cause of cancer death with 1,383,500 estimated new cases each year (1). This fact has generated an interest to obtain insight into breast tumorigenesis and also to develop drugs that effectively combat the disease. Currently, women with advanced breast cancer develop metastases which account significantly for morbidity and mortality. Ras is a proto-oncogene that is activated transiently as a response to extracellular signals such as growth factors, cytokines, and hormones which stimulate cell surface receptors (2). Approximately $90 \%$ of the activating mutations have been found in codons 12 (wild-type GGT) and 13 (wild-type GGC) of exon 1 identifying these codons as hot-spot mutation points. The most frequently observed types of mutations are $\mathrm{G} \rightarrow \mathrm{A}$ transitions and $\mathrm{G} \rightarrow \mathrm{T}$ transversions $(3,4)$.

As a member of the Ras GTPase superfamily (5), Rho-A is an oncogenic and a critical component of signaling pathways leading to downstream gene regulation (6-9). Rho family proteins are prominent members of the well-known Ras superfamily of small GTPases that can cycle between inactive GDP-bound state and active GTP-bound state and that exhibit intrinsic GTPase activities (10-12). Rho-A is frequently overexpressed in human cancer (13). In terms of function, several Rho GTPases have been shown to regulate diverse signal transduction pathways and are involved in a variety of biological processes, including cell morphology $(14,15)$, motility (16), proliferation (17) and apoptosis $(18,19)$. Recently, a number of studies has shown that Rho-A expression was upregulated in a group of malignancies, including breast cancer, colon cancer, lung cancer, and ovarian cancer (20-24) and that the expression level of Rho-A seemed to be positively correlated with the progress of these carcinomas, suggesting that Rho-A may play an important role in tumorigenesis and tumor progression.

Rac1, belonging to the Rho family, is a Ras-related small GTPase. Its activity is responsible for the regulation of diverse cellular behaviors including, formation of cortical actincontaining membrane ruffles, and induction of gene expression programs (25). Racl activity is implicated in various steps of oncogenesis including initiation, progression, invasion and metastasis $(26,27)$.

p53, considered as the 'guardian of the genome', is the most frequently mutated gene in human malignancies such as cancer, it is found inactivated in $\sim 50 \%$ of tumors of any 
location and histological type (generally, point mutations of one allele and deletion of the other allele). Present in an inactive form in normal cells, p53 becomes fully functional when activated in response to cell stress (either oncogenic or genotoxic stress). p53 activation leads to the upregulation of various target genes responsible for cell cycle arrest or apoptotic cell death, depending on the cellular environment. Due to its crucial tumor suppressor activity, TP53 thus appears to be an appealing target for gene therapy or pharmacological intervention in cancer treatment (28).

The signal transducers and activators of transcription (Stats) belong to a family of seven cytoplasmic proteins that function as signal messengers and transcription factors participating in cellular responses to cytokines and growth factors. Stat1 is deficient or inactive in many types of human tumors whereas some tumors have activated Stat1. Whether Stat1 affects tumor growth and metastasis is unclear (29-31).

Apoptosis (programmed cell death), is a process of cellular destruction that is required for the development and homeostasis of multicellular organisms (32). Apoptosis is characterized by cell shrinkage, condensation of nuclei and internucleosomal degradation of DNA. Cells defective in apoptosis tend to survive with excess DNA damage and thus lead to carcinogenesis by accumulating mutations (33). In chemotherapy, apoptosis is the predominant mechanism by which cancer cells die. However, even when the apoptotic machinery remains intact, survival signaling may antagonize the cell death by signals, such as growth factor, steroid hormone, neuropeptide and the activation of phosphatidylinositol 3-kinase and Akt $(34,35)$. In view of recent findings, specific patterns of resistance to chemotherapy can occur depending on the genetic or epigenetic abnormalities of the cancer cells $(36,37)$.

The Bax gene, a member of the Bcl-2 family and an apoptosis promoter, regulates the release of cytochrome $c$ from mitochondria (38), and its forced expression is known to lead to the activation of caspases and to programmed cell death $(39,40)$. However, it is controversial whether caspases are required for Bax-induced apoptosis. Both caspase-dependent cell death $(41,42)$ and caspase-independent cell death $(43)$ mediated by Bax have been reported. Several caspase-3-like proteases exist and it is even uncertain whether caspase- 3 is absolutely required in Bax-mediated cell death (44). Bcl-xL, one of several additional proteins with sequence homology to Bcl-2, is 233 amino acid protein with $43 \%$ sequence identity with Bcl-2 that suppresses cell death (45).

Caspase- 3 is a member of the cysteine protease family, which plays a crucial role in apoptotic pathways by cleaving a variety of key cellular proteins. Caspase-3 is the most widely studied of the effector caspases, it can be activated by diverse death-inducing signals, including the chemotherapeutic agents. It plays a key role in both the death receptor pathway, initiated by caspase-8, and the mitochondrial pathway, involving caspase-9. In addition, several studies have shown that caspase-3 activation is required for apoptosis induction in response to chemotherapeutic drugs e.g., taxanes, 5-fluorouracil (5-FU) and doxorubicin (46-48).

$\mathrm{NF}-\kappa \mathrm{B}$ has been implicated in many inflammatory and malignant diseases, such as breast cancer. NF- $\kappa B$ transcription factors play a crucial role in oncogenesis (49). NF- $\kappa \mathrm{B}$ is aberrantly activated in a wide range of human cancers, in which it promotes survival and malignancy by upregulating anti-apoptotic genes (50).

5-FU is a pyrimidine analog and is the most widely used chemotherapeutic agent for the treatment of a variety of solid cancers. Its mechanism of action has been attributed to the production of cytotoxic metabolites incorporated into RNA and DNA and inhibiting thymidylate synthase, finally leading to cell cycle arrest and apoptosis in cancer cells (51). The aim of this study was to evaluate 5-FU in cells transformed by low doses of ionizing radiation $\alpha$-particles in breast cancer cell lines (52) on apoptotic activity.

\section{Materials and methods}

Breast cancer cell lines. The immortalized breast cell line, MCF-10F (ATCC, Manassas, VA, USA) retains all the characteristics of normal epithelium in vitro, including anchorage-dependence, non-invasiveness and non-tumorigenicity in nude mice. This cell line was grown in DMEM/F-12 (1:1) medium supplemented with antibiotics $100 \mathrm{U} / \mathrm{ml}$ penicillin, $2.5 \mu \mathrm{g} / \mathrm{ml}$ amphotericin $\mathrm{B}, 100 \mu \mathrm{g} / \mathrm{ml}$ streptomycin (all from Life Technologies, Grand Island, NY, USA) and $0.5 \mu \mathrm{g} / \mathrm{ml}$ hydrocortisone (Sigma-Aldrich, St. Louis, MO, USA), $10 \mu \mathrm{g} / \mathrm{ml}$ and $5 \%$ equine serum (Biofluids, Rockville, MD, USA), and $0.02 \mu \mathrm{g} / \mathrm{ml}$ epidermal growth factor (Collaborative Research, Bedford, MA, USA). We used two cell lines from an in vitro experimental breast cancer model, the MCF-10F and Tumor2 cells. This model consisted of human breast epithelial cells in different stages of transformation (52). In brief, MCF-10F was exposed to low doses of high linear energy transfer (LET) $\alpha$-particle radiation $(150 \mathrm{keV} / \mu \mathrm{m})$ and subsequent growth in the presence or absence of $17 \beta$-estradiol at $10^{-8} \mathrm{M}$ (E) (Sigma-Aldrich) was evaluated. Tumor2, is a malignant and tumorigenic cell line obtained from Alpha5 $(60 c G y+E / 60 c G y+E)$ injected into the nude mice given rise to this cell line (52). The cells were incubated at $37^{\circ} \mathrm{C}$ with $5 \% \mathrm{CO}_{2}$ up to $70 \%$ of confluence. The other cell line used was MDA-MB-231, a metastatic human breast cancer cell line obtained from ATCC ${ }^{\circledR}$ HTB- $26^{\mathrm{TM}}$ and grown in RPMI supplemented with $10 \%$ fetal bovine serum.

Cell viabilityassay. The cytotoxic effect of 5-FU on cell viability was examined using the 3-(4,5-dimethylthiazol-2-yl)-2,5-diphenyltetrazolium bromide (MTT) assay in breast cancer cell lines. Briefly, cells were seeded in 24-well culture plates at a density of $5 \times 10^{4}$ cells/well. After cells were attached, the cells were treated with 5-FU at different concentrations ranging from $0-5 \mu \mathrm{M}$. The concentration of DMSO was $0.01 \%(\mathrm{v} / \mathrm{v})$. The plates were incubated at $37^{\circ} \mathrm{C}$ with $5 \% \mathrm{CO}_{2}$ for $48 \mathrm{~h}$. The control cells received the vehicle only. After 48 -h incubation, the medium was removed, and $0.5 \mu \mathrm{mol} / 1 \mathrm{MTT}$ was added into the wells. After another $4 \mathrm{~h}, 150 \mu \mathrm{l}$ DMSO was added into each well to dissolve the crystal. The absorbance was read at $570 \mathrm{~nm}$ on a microplate reader (Autobio Labtec Instruments, Zhengzhou, China). The drug concentration yielding 50\% cell inhibition $\left(\mathrm{LD}_{50}\right)$ was determined. The treatment groups were compared with the control group and the results were expressed as percentage of viable cells. All experiments were performed in triplicate. 
Table I. Selected primers for target genes to develop cDNA probes.

\begin{tabular}{|c|c|c|}
\hline $\begin{array}{l}\text { Gene } \\
\text { name }\end{array}$ & $\begin{array}{l}\text { Product } \\
\text { length }(\mathrm{bp})^{\mathrm{a}}\end{array}$ & Primer sequence ${ }^{\mathrm{b}}$ \\
\hline$H$-ras & 112 & $\begin{array}{l}\text { 1-CCAGTACAGGGAGCAGAT } \\
\text { 1'-GAGCCTGCCGAGATTCCACA }\end{array}$ \\
\hline Rho-A & 140 & $\begin{array}{l}\text { 1-CCATCATCCTGGTTGGGAAT } \\
\text { 1'-CATGTACCCAAAAGCGCCA }\end{array}$ \\
\hline p53 & 128 & $\begin{array}{l}\text { 1-CCTCAGCATCTTATCCGAGTGG } \\
\text { 1'-TGGATGGTGGTACAGTCAGAGC }\end{array}$ \\
\hline$B c l-x L$ & 211 & $\begin{array}{l}\text { 1-CTGAATCGGAGATGGAGACC } \\
\text { 1'-TGGGATGTCAGGTCACTGAA }\end{array}$ \\
\hline Bax & 143 & $\begin{array}{l}\text { 1-GCGAGTGTCTCAAGCGCATC } \\
\text { 1'-CCAGTTGAAGTTGCCGTCAGAA }\end{array}$ \\
\hline $\begin{array}{l}N F-\kappa B \\
(\text { RelA) }\end{array}$ & 114 & $\begin{array}{l}\text { 1-ATCTGCCGAGTGAACCGAAACT } \\
\text { 1'-CCAGCCTGGTCCCGTGAAA }\end{array}$ \\
\hline$\beta$-actin & 569 & $\begin{array}{l}\text { 1-ACTACCTCATGAAGATCCTC } \\
\text { 1'-TAGAAGCATTTGCGGTGGACGATGG }\end{array}$ \\
\hline
\end{tabular}

${ }^{a}$ Length of cDNA product amplified by gene-specific RT-qPCR analysis. ${ }^{b} \mathrm{PCR}$ primer sequences used to generate a product of the indicated size, listed in 5'-3' orientation. 1 , forward; $1^{\prime}$, reverse.

Reverse transcription quantitative-polymerase chain reaction $(R T-q P C R)$ analysis. Total RNA was extracted with TRIzol (Invitrogen, Carlsbad, CA, USA), and the concentration and purity of RNA were determined using a UV spectrophotometer. Total RNA was reverse transcribed into cDNA using High capacity cDNA Reverse Transcription kit and 10 units of RNase inhibitor (both from Applied Biosystems, Carlsbad, CA, USA) according to the manufacturer's protocol. A CFX 96 Touch Real-Time PCR Detection Systems (Bio-Rad Laboratories, Hercules, CA, USA) was used with an aliquot of cDNA $(2 \mu \mathrm{l})$ in $20 \mu \mathrm{l}$ qPCR reaction containing SYBR-Green PCR Master Mix (Agilent, La Jolla, CA, USA) for measurement of target genes such as $c$-Ha-ras, Rho-A, NF- $\kappa B, B c l-x L, B a x, p 53$ and $\beta$-actin was used as reference to obtain the relative fold-change for target genes using the comparative $\mathrm{Ct}$ method and using Bio-Rad CFX Manager 2.1 software. Relative expression was always normalized to the average in normal breast cells. Table I shows the primers for the genes selected to develop cDNA probes.

Western blot analysis. Cells were lysed with $1 \mathrm{ml}$ lysis buffer (pH 7.2) (Tris Base (50 mM), NaCl (100 mM), EDTA (1 mM), orthovanadate $(1 \mathrm{mM})$, PMSF $(1 \mathrm{mM})$, Triton X-100 $(0,1 \%)$ and centrifuged $(13,200 \mathrm{rpm} \times 15 \mathrm{~min})$. The supernatant with cellular proteins were dissolved in SDS-PAGE sample solution $(60 \mathrm{mM})$ Tris, $\mathrm{pH} 6.5,10 \%$ (w/v) glycerol, $5 \%(\mathrm{w} / \mathrm{v})$ $\beta$-mercaptoethanol, $20 \%(\mathrm{w} / \mathrm{v})$ SDS, and $0.025 \%(\mathrm{w} / \mathrm{v})$ bromophenol blue and denatured by boiling $(2 \times 5 \mathrm{~min})$, and vortex mixing $(2 \times 30 \mathrm{seg})$. The total amount of protein was $30 \mu \mathrm{g}$ in each lane with standard protein markers (BioRad Laboratories). After fractionation by SDS-PAGE on gels $(7 \times 14 \mathrm{~cm})$, proteins were electro-blotted onto PVDF membrane (Amersham Biosciences, Buckinghamshire, UK) using a blotting apparatus (Bio-Rad Laboratories). Prestained SDS-PAGE (Standards) blots were blocked for $2 \mathrm{~h}$ in $10 \%$ defatted dry milk-TBS-0.1\% Tween-20 and then incubated for $2 \mathrm{~h}$ at room temperature with corresponding primary antibodies (1:200) Rac1 (sc-217), Rho-A (sc-418), Stat1 (sc-417), caspase-3 (sc-7148), Bax (sc-7480), NF- $\kappa$ B (sc-53744) and $\beta$-actin (sc-47778) followed by incubation with secondary peroxidase-conjugated mouse IgG $(1: 5,000)$ (Cell Signaling Technology, Danvers, MA, USA) in 5\% defatted dry milk-TBS-0.1\% Tween-20. All steps were performed at room temperature, and blots were rinsed between incubation steps with TBS-0.1\% Tween-20. Cell blots were probed with mouse anti $\beta$-actin antibody as control. Immunoreactive bands were visualized by using the $\mathrm{ECL}^{\mathrm{TM}}$ Western Blotting Detection Reagent detection method (Amersham, Dübendorf, Switzerland) and exposure of the membrane to X-ray film. Protein determination was performed using the Bicinchoninic Acid Method (Bio-Rad Laboratories) and BSA as the standards. Experiments were performed in triplicate.

Apoptosis assay. Annexin V, a $\mathrm{Ca}^{2+}$-dependent phospholipid binding protein, has a strong binding affinity for phosphatidylserine (PS) which is inside of cell membrane in normal cells and is transferred to the surface during the early stage of cell apoptosis. Thus, apoptotic cells were quantified using the Annexin V-FITC apoptosis detection kit (Beckman Coulter, Fullerton, CA, USA) after cells were treated with 5-FU at $2 \mu \mathrm{M}$ for $48 \mathrm{~h}$. MCF-10F and Tumor 2 cell lines were cultured until $70 \%$ confluent, then 5-FU with indicated concentrations was added. After $48 \mathrm{~h}$, cells were trypsinized and washed twice with cold PBS, and then resuspended in $1 \mathrm{X}$ binding buffer with $10 \mu \mathrm{l}$ of Annexin V-FITC and $20 \mu \mathrm{l}$ of 7-aminoactinomycin D (7-AAD, a nucleic acid dye) at $1 \times 10^{6}$ cells $/ \mathrm{ml}$ in a total volume of $100 \mu \mathrm{l}$. Cells were gently mixed and incubated in the dark for $15 \mathrm{~min}$ at room temperature. A quantity of $1 \mathrm{X}$ binding buffer $(400 \mu \mathrm{l})$ was then added to a clean test tube and the number of apoptotic cells was quantified using a flow cytometer (Beckman Coulter FC500 Flow Cytometry System; Beckman Coulter) within $1 \mathrm{~h}$. Cells that stain positive for Annexin V-FITC and negative for 7-AAD are undergoing apoptosis; cells that stain positive for both Annexin V-FITC and 7-AAD are either in the endstage of apoptosis, are undergoing necrosis, or are already dead; cells that stain negative for both Annexin V:FITC and 7-AAD are alive and not undergoing apoptosis. Analysis was performed by Beckman Coulter FC500 Flow Cytometry System with CXP Software (Beckman Coulter). All experiments were performed at least three times.

Statistical analysis. Data are expressed as the average \pm standard error of the mean (SEM). Comparisons of multiple groups were performed between treated groups and controls carried out by ANOVA and Dunnet's test. P-values of $\mathrm{p}<0.05$ and $\mathrm{p}<0.01$ were considered to be significant. Lethal dose at $50 \%\left(\mathrm{LD}_{50}\right)$ was calculated by a non-linear regression curve using GraphPad Prism 5.0 for Windows (GraphPad Software, San Diego, CA, USA). Assays were performed at least three times independently. 
A

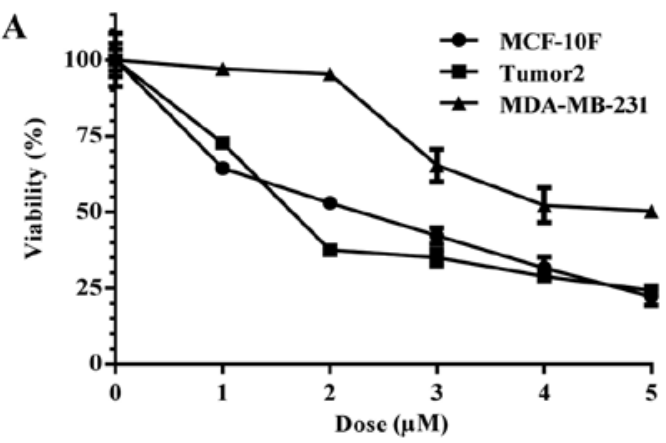

B

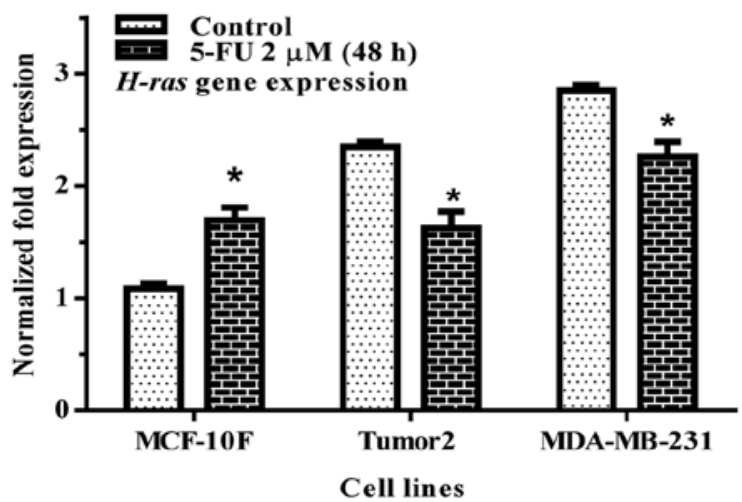

C

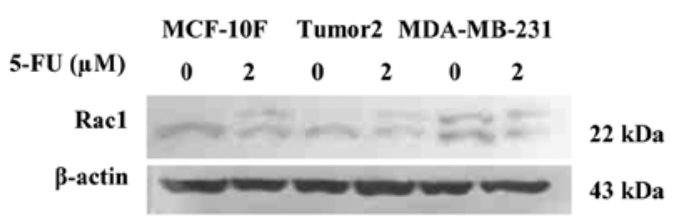

D

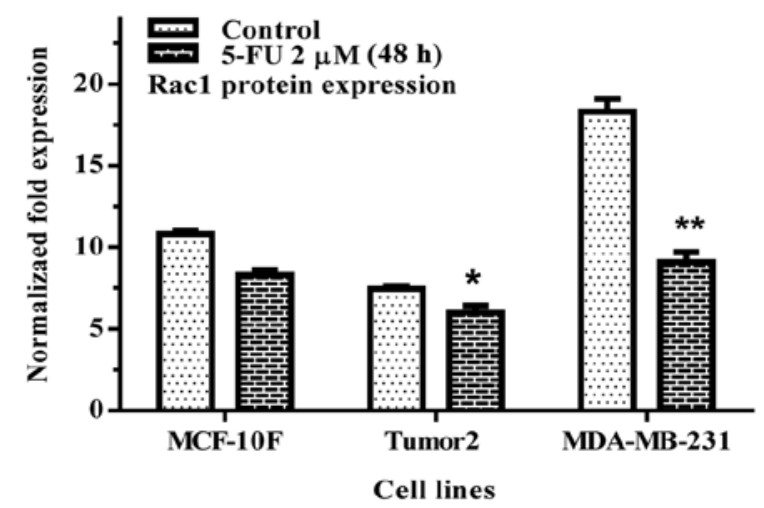

Figure 1. (A) Effect of 5-FU on cell viability. MCF-10F, Tumor2 and MDA-MB-231 cell lines were treated with different doses of 5-FU (from 0 to $5 \mu \mathrm{M}$ ) and incubated for $48 \mathrm{~h}$, and determined by using the MTT assay and an automated cell counter. (B) $H$-ras gene expression and (C and D) Rac1 protein expression were evaluated. Bars represent the mean \pm SEM of three independent experiments. ${ }^{*} p<0.05$ and ${ }^{* *} p<0.01$ vs. control group and their counterparts. $\beta$-actin was used as an endogenous control. Data represent the means \pm SEM of three independent experiments. ${ }^{*} p<0.05$ and ${ }^{* *} p<0.01$ vs. counterparts.

\section{Results}

MTT assay was carried out to evaluate the metabolic activity of living cells as indicator of viability in MCF-10F, Tumor2 and MDA-MB-231 cell lines and to determine the dose to be used in the experiments. Concentration range of $0-5 \mu \mathrm{M}$ was used of 5-FU for $48 \mathrm{~h}$ to calculate that $\mathrm{LD}_{50}$ values for all cell lines tested. Results in Fig. 1A showed that the mean $\mathrm{LD}_{50}$ was at $2 \mu \mathrm{M}$ after $48 \mathrm{~h}$. Therefore, all the following experiments were carried out with this concentration of 5-FU.

Ras family is related to cell proliferation in cancer cells. $H$-ras gene expression was studied by RT-qPCR. Results of the experiments indicated that 5-FU significantly decreased $H$-ras gene expression in Tumor2 and MDA-MB-231 cell lines (Fig. 1B). Rac1 (Fig. 1C and D) protein expression was decreased in Tumor 2 and MDA-MB-231 cells $(\mathrm{p}<0.05$ and $\mathrm{p}<0.01)$ in comparison with its counterpart.

Rho-A is member of Ras family known to regulate the actin cytoskeleton and it is distributed in the nuclei of cancer cells. Rho-A gene and protein expression were studied by RT-qPCR and western blot analysis, respectively. Results of the experiments indicated that 5-FU significantly decreased Rho-A gene expression and protein expression of the Tumor 2 cells $(\mathrm{p}<0.01)$ in comparison with its counterpart, however, the MDA-MB-231 cells were not altered (Fig. 2A-C).

Analysis of gene expression indicated that 5-FU decreased p53 in Tumor 2 cells in comparison to its counterparts. However, MDA-MB-231 cells showed an increase in gene expression in comparison with their counterparts (Fig. 2D). Fig. 2E and F show Stat1 protein expression. There was no effect on Stat1 either in Tumor2 or in MDA-MB-231 cells.

The apoptotic activity of 5-FU on MCF-10F, Tumor2 and MDA-MB-231 cell lines were analyzed. Results indicated that $B c l-x L$ (Fig. 3A) gene expression significantly decreased in MDA-MB-231 with regard to its counterpart $(\mathrm{p}<0.01)$. However, there was no effect in Tumor 2 cells. 5-FU significantly increased caspase- 3 protein expression in Tumor2 and MDA-MB-231 cells in comparison to its counterparts (Fig. 3B and C). It also increased Bax gene (Fig. 3D) and protein (Fig. 3E and F) expression in Tumor2 and MDA-MB-231 cell lines. Apoptotic cells were also measured by flow cytometry, the results indicated $21.5 \%$ of cell death in the control MCF-10F and 80\% in Tumor2 cells (Fig. 4).

The activation of NF- $\mathrm{KB}$ is frequently observed in breast cancer cells. 5-FU significantly decreased NF- $\kappa B$ gene expression in MDA-MB-231 but not in Tumor2 in comparison to its counterparts (Fig. 5A). 5-FU also decreased protein expression in Tumor2 cell, but not in MDA-MB-231 cells (Fig. 5B-D), where we observed and increase in the expression in both subunits p105 and p50 kDa as shown in Fig. 5B.

\section{Discussion}

Breast cancer is one of the most common causes of cancerrelated death among women (1). 5 -FU is frequently used to treat 
A

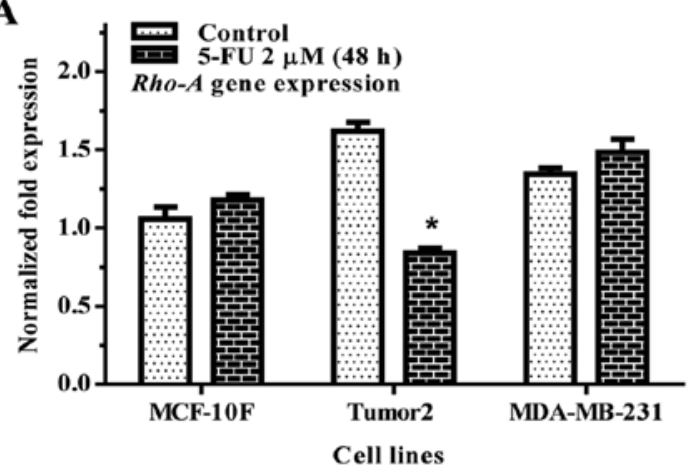

B

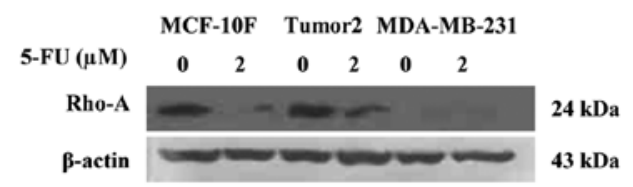

C

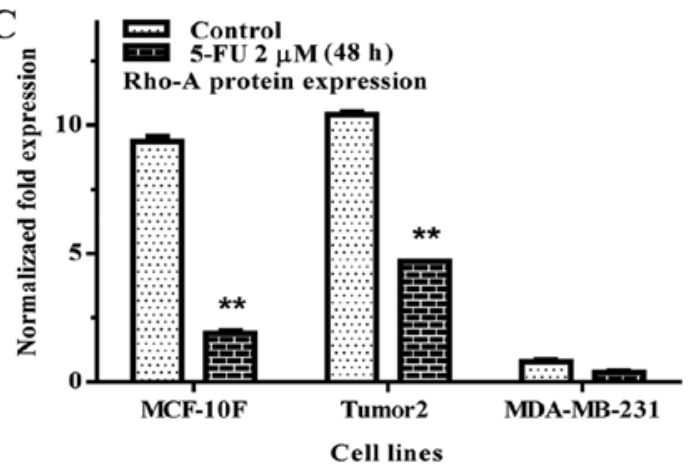

D

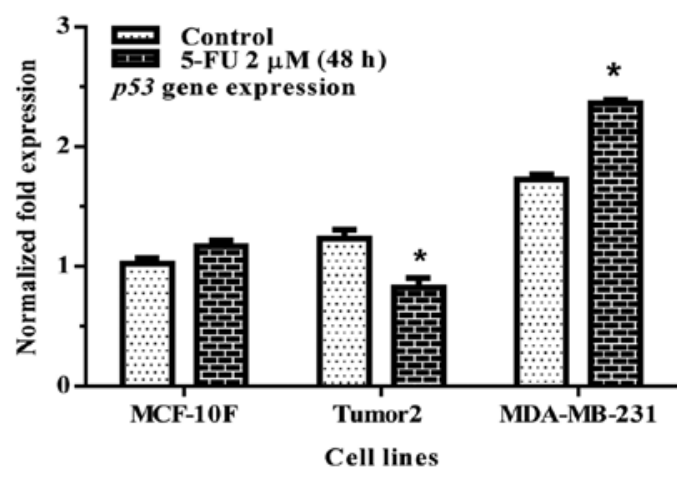

$\mathbf{E}$

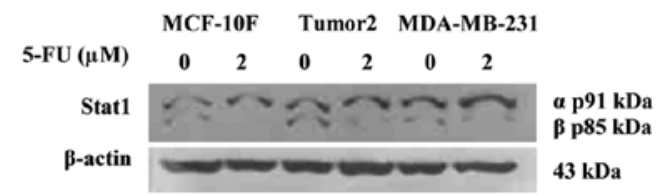

$\mathbf{F}$

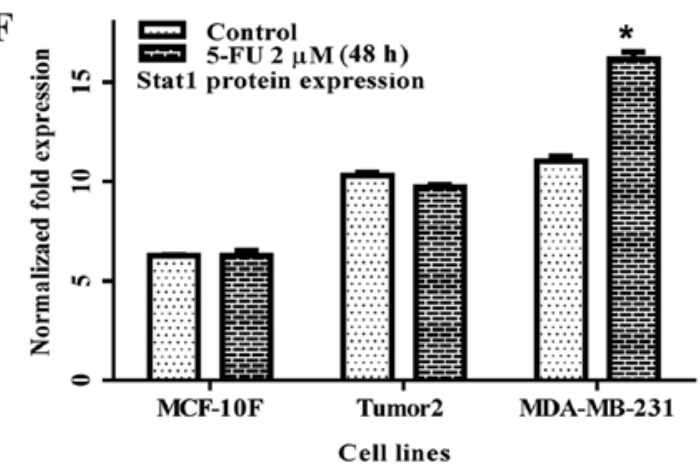

Figure 2. Rho-A gene and protein expression: Effect of 5-FU in MCF-10F, Tumor2 and MDA-MB-231 cell lines (A-C) determinated by RT-qPCR and western blot analyses, respectively. $\beta$-actin was used as control for loading. (D) p53 gene expression and (E and F) Stat1 protein expression were evaluated. Band density of the specific protein was analyzed with Adobe Photoshop program software and the results were expressed as average density to $\beta$-actin. Graphs represent the relative grade of luminescence to assess the protein level of the cell lines. Bars represent the mean \pm SEM of three independent experiments. ${ }^{* *}$ p $<0.01$ vs. counterpart.

breast cancer. This agent can inhibit breast cancer progression by a variety of different mechanisms such as apoptosis by affecting cell death pathways. Therefore, several clinical trials are currently under investigation to overcome drug resistance due to modulation of apoptosis (51). In the present study, the in vitro effects of 5-FU in breast cancer cell lines were evaluated by several parameters. 5-FU showed a direct apoptotic activity in breast cancer cell lines, which is in agreement with results from previous studies (51).

5-FU decreased $H$-ras gene and protein expression in Tumor2 and MDA-MB-231 cell lines in comparison to its counterparts and MCF-10F. Authors have demonstrated that resistance to 5-FU may result from low levels of GTPase-activating proteins, such as N-ras and H-ras in tumor cells (20). 5-FU has been shown to be a highly effective inhibitor of human cell proliferation by inactivating the Ras/ERK pathway $(20,21)$. The effects of H-ras on cell motility appeared to be through activation of a MAP kinase cascade, presumably via the Ras effector Raf (24).

Rac1 is responsible for Ras-induced phenotype changes by regulating motility mammary epithelial cells (53). Our results have shown that 5-FU significantly decreased Rac1 protein expression in Tumor2 and MDA-MB-231 cells. Rac is related to a profound change in cell phenotype such as motility, invasiveness, and resistance to apoptosis or the ability to adapt to environmental changes and continue to invade successfully (54). Anti-apoptotic activity of Rac has been indicated, although the molecular mechanism through which Rac inactivation promotes apoptosis has yet to be elucidated (55).

Previous studies have highlighted the role of signal transduction pathways controlled by the Rho family of small GTPases (21). 5-FU decreased Rho-A gene and protein expression in Tumor 2 cell line in comparison to their counterparts. It is of interest to note that MDA-MB-231 were not altered by this chemotherapeutic drug which is highly resistant. The inhibition of Rho proteins may provide a possibility to reduce metastasis and apoptosis. Recent studies have indicated that 5-FU induced apoptotic effects in myeloma cells in vitro (19-27).

p53 acts as a transcription regulator and has been shown to block the entry of DNA-damaged cells into the S-phase and also to trigger an apoptotic pathway in many transformed cells by inducing the expression of a set of genes related to the control of cell proliferation (28). The present results indicated that p53 gene expression decreased by $5-\mathrm{FU}$ in Tumor 2 in 


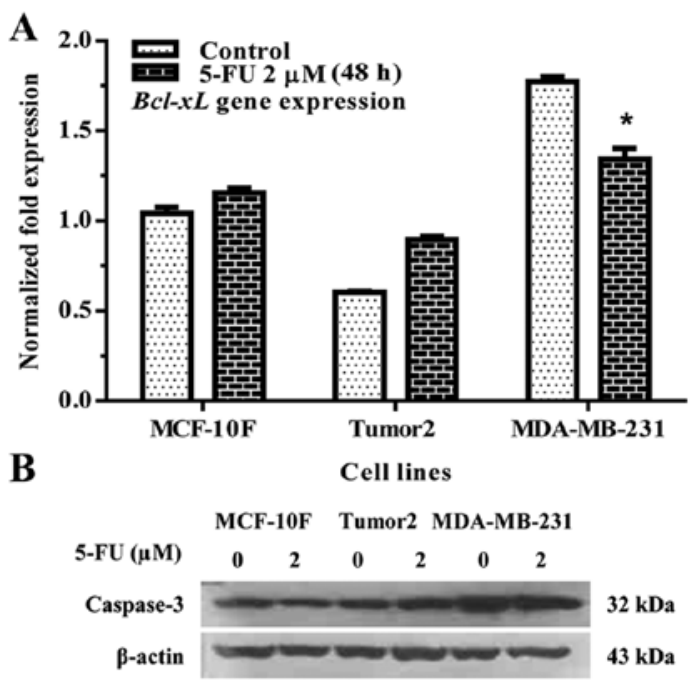

D

C

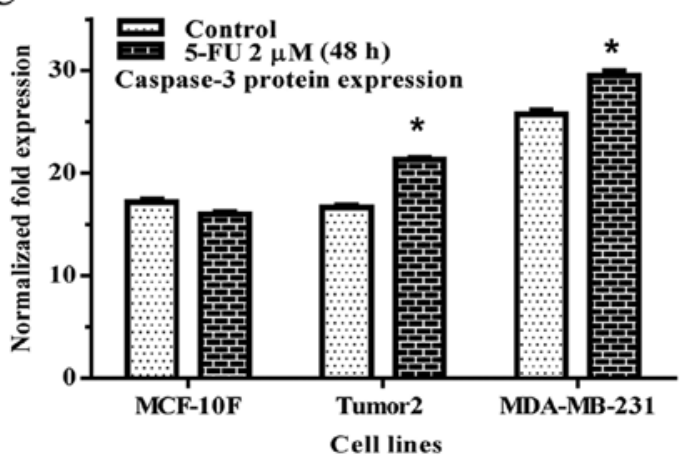

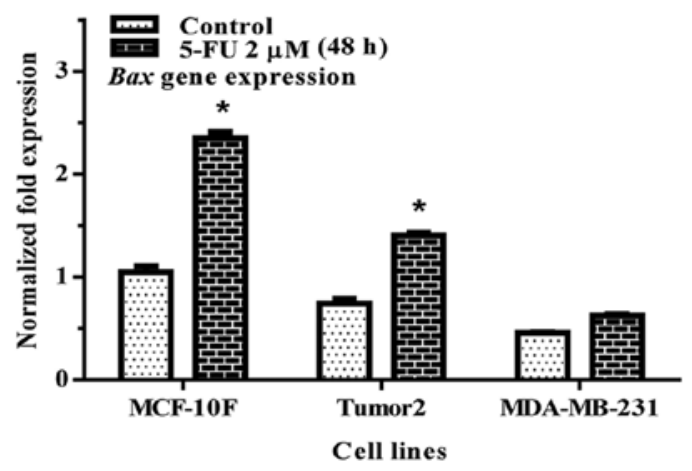

MCF-10F Tumor2 MDA-MB-231

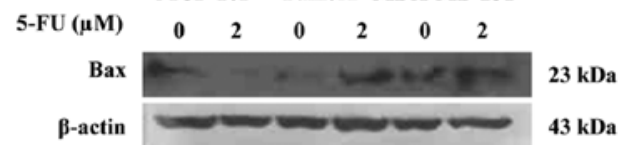

$\mathbf{F}$

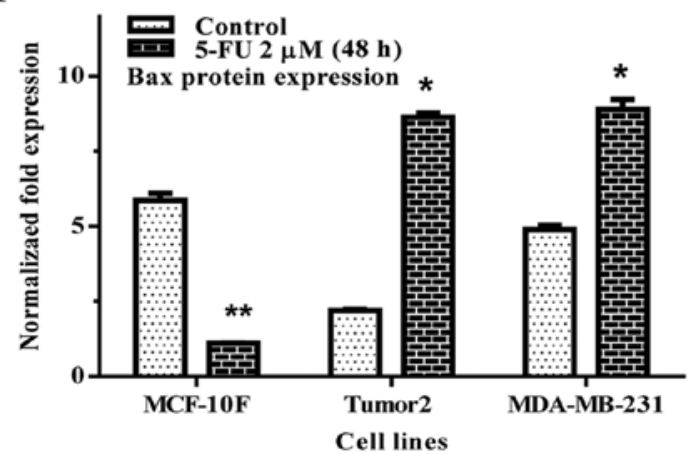

Figure 3. Effect of 5-FU on (A) Bcl- $x L$ and (D) Bax gene expression by RT-qPCR and (C) caspase-3 and (E and F) Bax protein expression by western blotting analysis in MCF-10F, Tumor2 and MDA-MB-231 cell lines. $\beta$-actin was used as an endogenous control gene. Bars represent the mean \pm SEM of three independent experiments. ${ }^{*} \mathrm{p}<0.05$ and ${ }^{* * *} \mathrm{P}<0.01$ vs. counterparts.

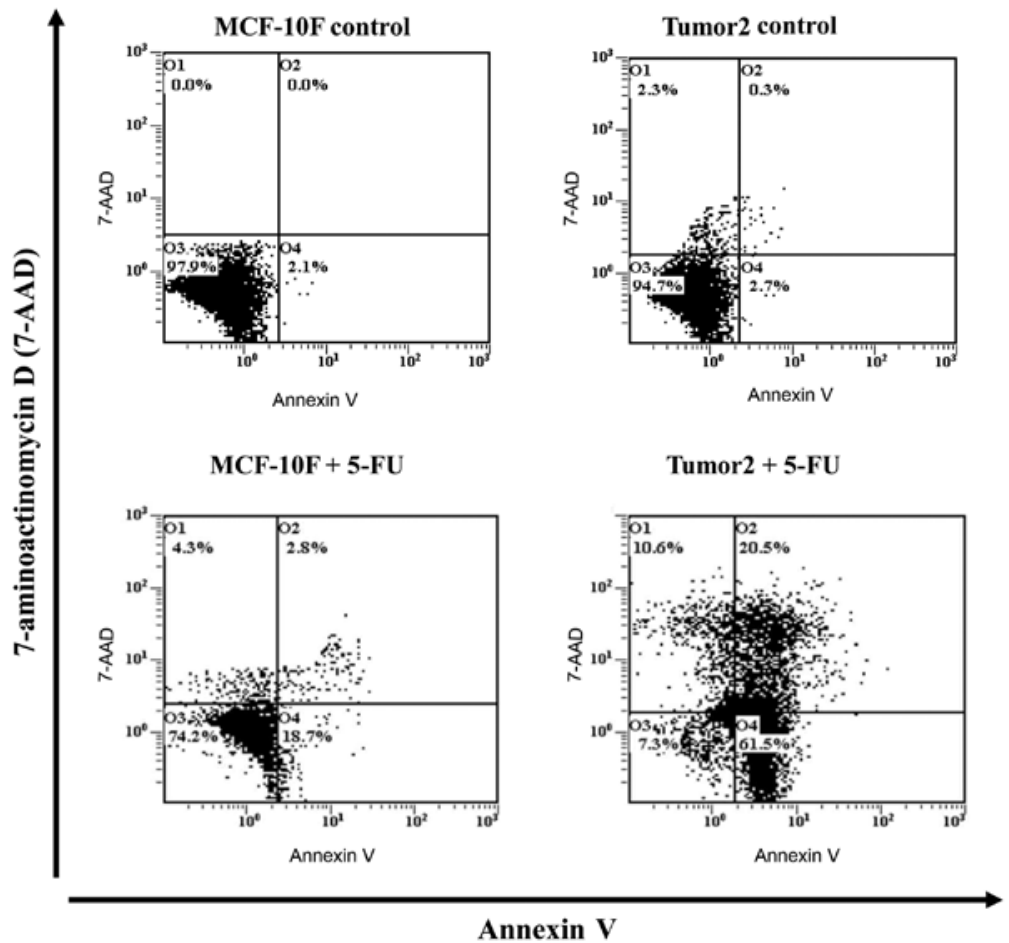

Figure 4. Flow cytometric analysis for apoptosis of breast cancer cells: apoptotic effects of 5-FU ( $2 \mu \mathrm{M} / 48 \mathrm{~h})$ were evaluated in MCF-10F and Tumor2 cell lines compared with their counterparts. Upper left quadrant (O1) indicates cells undergoing necrosis; upper right quadrant (O2), cells at the end stage of apoptosis; lower left quadrant (O3), cells that are viable, or no measurable apoptosis and lower right quadrant (O4), cells undergoing apoptosis. The percentage of the cells in apoptosis was determined by CXP software analysis. 


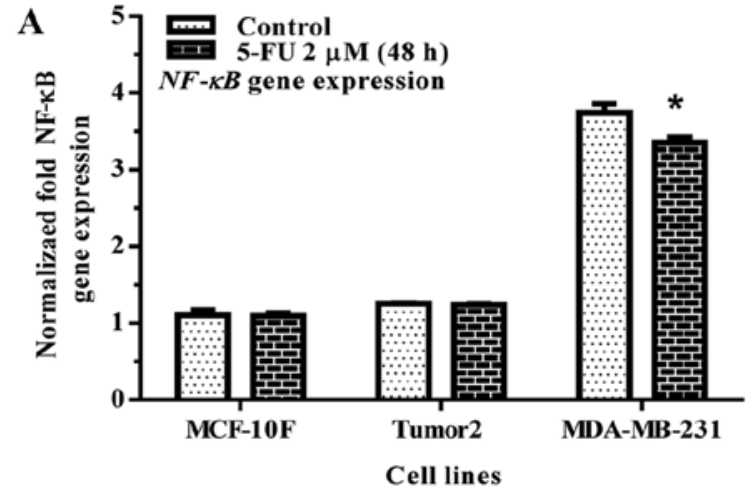

B

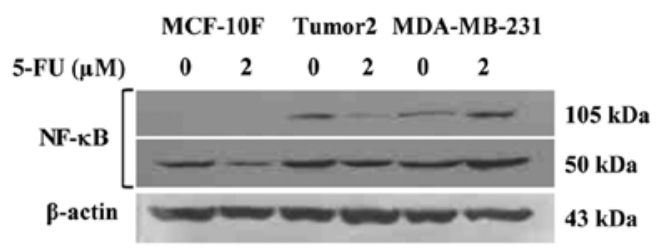

C

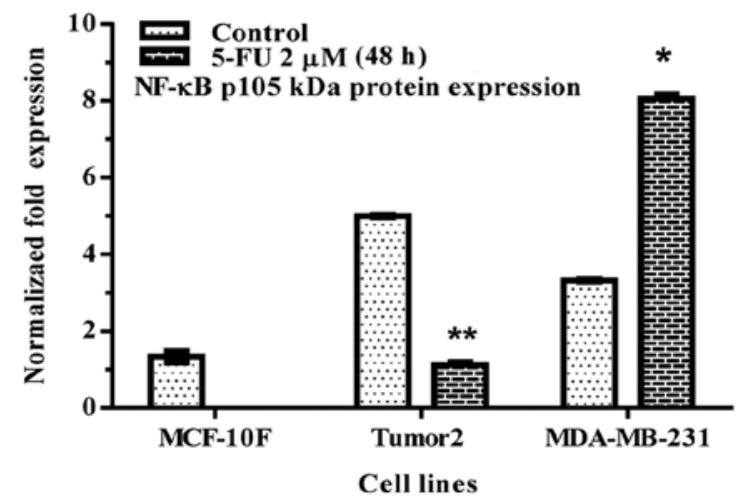

D

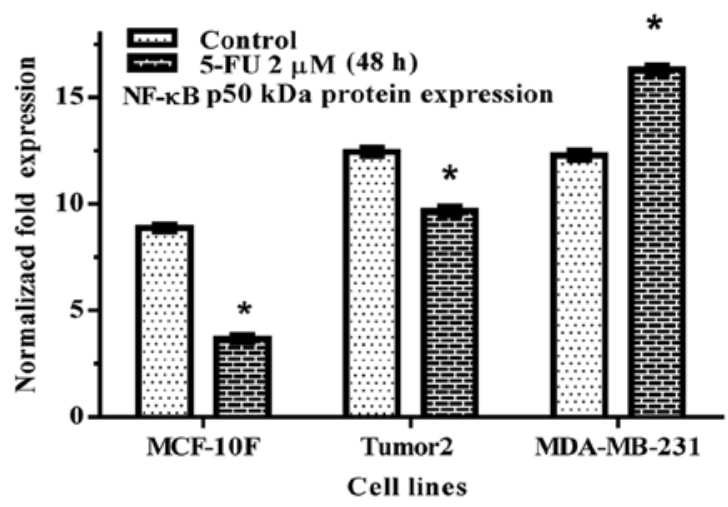

Figure 5. Effect of 5-FU on (A-D) $N F-\kappa B$ gene and protein expression in MCF-10F, Tumor2 and MDA-MB-231 cell lines by RT-qPCR and western blotting analysis. $\beta$-actin was used as an endogenous control gene. Bars represent the mean \pm SEM of three independent experiments. ${ }^{* * *} \mathrm{p}<0.01$ vs. counterparts.

comparison to its counterpart. Others, have showed that 5-FU induces apoptosis of human gastric cancer cells via wild-type p53 gene expression (56) which is consistent with our results. In addition to the high levels of anti-apoptotic Bcl-2 and $\mathrm{Bcl}-\mathrm{xL}$ proteins combined with a low level of Bax were correlated to high 5-FU resistance of wild-type p53 cell lines (57). 5-FU did not affect p53 gene expression in MDA-MB-231 cell line; however, this cell line as well as T47D, or SKBR-3 with GnRH-p53 in combination with 5-FU significantly enhanced p53-activated apoptotic signals including BAX translocation to mitochondria, and activated caspase-3. Intratumoral injection of the GnRH-p53 protein inhibited MDA-MB-231 xenograft growth and induced p53-mediated apoptosis in the tumors (58).

Stat1 participates in regulation of tumor angiogenesis, growth, and metastasis (29). Our results did not show any significant difference in Stat1 protein expression with the treatment of 5-FU in Tumor2 and MDA-MB-231. Stat1 has been shown to be associated with cell growth modulation and cell death signaling (59). This implied that Stat1 may have a modulatory role in cell death signaling when tumor cell growth is blocked by another Stat such as Stat3 inhibition (59).

The caspases, a family of cysteine proteases, are major mediators of the execution phase of apoptosis; possibly by direct activation of the death receptor or following mitochondrial changes $(57,58)$. The cytotoxic effect of 5-FU induced apoptosis in cancer cells. Our results showed that 5-FU significantly increased caspase-3 expression in Tumor 2 and MDA-MB-231 cell lines suggesting activation of apoptosis. Other authors have confirmed that 5-FU induced increased activity of caspase- 3 and $-8(57,58)$.
$\mathrm{NF}-\mathrm{kB}$ is an important signaling pathway involved in chemoresistance induced by 5 -FU. Constitutive activation of $\mathrm{NF}-\mathrm{KB}$ is observed in several cancer cells and such activation results in the control of a signaling network, which includes the expression of anti-apoptotic genes, cell cycle regulatory genes and genes encoding cell surface receptors. The activation of $\mathrm{NF}-\mathrm{kB}$ is frequently observed in breast cancer cells. The present study shows that 5-FU decreased NF- $\mathrm{KB}$ gene expression in MDA-MB-231. 5-FU also decreased protein expression in Tumor 2 cell line in comparison to its counterparts. It has been indicated that inhibition of inducible NF- $\mathrm{kB}$ activity reduces chemoresistance to 5-FU in human stomach cancer cell line (60). Other studies have shown that downregulation of NF- $\mathrm{\kappa B}$ was able to enhance therapeutic efficacy of 5-FU (60-63).

The regulation of the genes by NF- $\mathrm{KB}$ is related to apoptosis (60) since it is a key positive regulator of cancer cell proliferation and survival. It has the ability to transcriptionally activate many pro-survival and anti-apoptotic genes such as Bax and Bcl-xL (64). In the present study, 5-FU decreased genes related to apoptosis such as Bcl-xL in Tumor 2 cell line. It can be concluded that 5-FU may exert apoptotic activity in breast cancer cells transformed by low doses of ionizing $\alpha$-particles in vitro regulating Bax and Bcl-xL and NF- $\kappa \mathrm{B}$ expression, respectively.

\section{Acknowledgements}

The technical assistance of Guiliana Rojas, Georgina Vargas and Leodán Crispin is greatly appreciated. This study was supported by Grant support FONDECYT \#1120006 (GMC) and MINEDUC-UTA (GMC). 


\section{References}

1. Jemal A, Bray F, Center MM, Ferlay J, Ward E and Forman D Global cancer statistics. CA Cancer J Clin 61: 69-90, 2011.

2. Campbell SL, Khosravi-Far R, Rossman KL, Clark GJ and Der CJ: Increasing complexity of Ras signaling. Oncogene 17: $1395-1413,1998$.

3. Bos JL, Fearon ER, Hamilton SR, Verlaan-de Vries M, van Boom JH, van der Eb AJ and Vogelstein B: Prevalence of ras gene mutations in human colorectal cancers. Nature 327 293-297, 1987

4. Finkelstein SD, Sayegh R, Christensen S and Swalsky PA: Genotypic classification of colorectal adenocarcinoma. Biologic behavior correlates with K-ras-2 mutation type. Cancer 71 $3827-3838,1993$

5. Bourne HR, Sanders DA and McCormick F: The GTPase superfamily: Conserved structure and molecular mechanism. Nature 349: 117-127, 1991.

6. Khosravi-Far R, Solski PA, Clark GJ, Kinch MS and Der CJ Activation of Rac1, RhoA, and mitogen-activated protein kinases is required for Ras transformation. Mol Cell Biol 15: 6443-6453, 1995.

7. Moorman JP, Bobak DA and Hahn CS: Inactivation of the small GTP binding protein Rho induces multinucleate cell formation and apoptosis in murine T lymphoma EL4. J Immunol 156: 4146-4153, 1996

8. Perona R, Esteve P, Jiménez B, Ballestero RP, Ramón y Cajal S and Lacal JC: Tumorigenic activity of rho genes from Aplysia californica. Oncogene 8: 1285-1292, 1993.

9. Prendergast GC, Khosravi-Far R, Solski PA, Kurzawa H, Lebowitz PF and Der CJ: Critical role of Rho in cell transformation by oncogenic Ras. Oncogene 10: 2289-2296, 1995.

10. Etienne-Manneville S and Hall A: Rho GTPases in cell biology. Nature 420: 629-635, 2002.

11. Sahai E and Marshall CJ: RHO-GTPases and cancer. Nat Rev Cancer 2: 133-142, 2002

12. Wherlock $M$ and Mellor $H$ : The Rho GTPase family: A Racs to Wrchs story. J Cell Sci 115: 239-240, 2002.

13. Yoshioka K, Nakamori S and Itoh K: Overexpression of small GTP-binding protein RhoA promotes invasion of tumor cells. Cancer Res 59: 2004-2010, 1999.

14. Paterson HF, Self AJ, Garrett MD, Just I, Aktories K and Hall A Microinjection of recombinant $\mathrm{p} 21$ rho induces rapid changes in cell morphology. J Cell Biol 111: 1001-1007, 1990.

15. Ramakers GJ and Moolenaar WH: Regulation of astrocyte morphology by RhoA and lysophosphatidic acid. Exp Cell Res 245: 252-262, 1998.

16. Soga N, Namba N, McAllister S, Cornelius L, Teitelbaum SL, Dowdy SF, Kawamura J and Hruska KA: Rho family GTPases regulate VEGF-stimulated endothelial cell motility. Exp Cell Res 269: 73-87, 2001

17. Sahai E, Olson MF and Marshall CJ: Cross-talk between Ras and Rho signalling pathways in transformation favours proliferation and increased motility. EMBO J 20: 755-766, 2001.

18. Senger DL, Tudan C, Guiot MC, Mazzoni IE, Molenkamp G, LeBlanc R, Antel J, Olivier A, Snipes GJ and Kaplan DR: Suppression of Rac activity induces apoptosis of human glioma cells but not normal human astrocytes. Cancer Res 62: 2131-2140, 2002.

19. Embade N, Valerón PF, Aznar S, López-Collazo E and Lacal JC: Apoptosis induced by Rac GTPase correlates with induction of FasL and ceramides production. Mol Biol Cell 11: 4347-4358, 2000.

20. Abraham MT, Kuriakose MA, Sacks PG, Yee H, Chiriboga L, Bearer EL and Delacure MD: Motility-related proteins as markers for head and neck squamous cell cancer. Laryngoscope 111: $1285-1289,2001$

21. Fritz G, Just I and Kaina B: Rho GTPases are over-expressed in human tumors. Int J Cancer 81: 682-687, 1999.

22. Horiuchi A, Imai T, Wang C, Ohira S, Feng Y, Nikaido T and Konishi I: Up-regulation of small GTPases, RhoA and RhoC, is associated with tumor progression in ovarian carcinoma. Lab Invest 83: 861-870, 2003.

23. Kamai T, Arai K, Tsujii T, Honda M and Yoshida K Overexpression of RhoA mRNA is associated with advanced stage in testicular germ cell tumour. BJU Int 87: 227-231, 2001.

24. Kamai T, Kawakami S, Koga F, Arai G, Takagi K, Arai K, Tsujii T and Yoshida KI: RhoA is associated with invasion and lymph node metastasis in upper urinary tract cancer. BJU Int 91 : 234-238, 2003
25. Jaffe $A B$ and Hall A: Rho GTPases: Biochemistry and biology Annu Rev Cell Dev Biol 21: 247-269, 2005.

26. Ellenbroek SI and Collard JG: Rho GTPases: Functions and association with cancer. Clin Exp Metastasis 24: 657-672, 2007.

27. Vega FM and Ridley AJ: Rho GTPases in cancer cell biology. FEBS Lett 582: 2093-2101, 2008

28. Olivier M, Eeles R, Hollstein M, Khan MA, Harris CC and Hainaut P: The IARC TP53 database: New online mutation analysis and recommendations to users. Hum Mutat 19: 607-614, 2002.

29. Huang S, Bucana CD, Van Arsdall M and Fidler IJ: Stat1 negatively regulates angiogenesis, tumorigenicity and metastasis of tumor cells. Oncogene 21: 2504-2512, 2002.

30. Schindler C, Levy DE and Decker T: JAK-STAT signaling: From interferons to cytokines. J Biol Chem 282: 20059-20063, 2007.

31. Stark GR and Darnell JE Jr: The JAK-STAT pathway at twenty. Immunity 36: 503-514, 2012.

32. McKenna SL, McGowan AJ and Cotter TG: Molecular mechanisms of programmed cell death. Adv Biochem Eng Biotechnol 62: 1-31, 1998.

33. Leist $M$ and Jäättelä M: Four deaths and a funeral: From caspases to alternative mechanisms. Nat Rev Mol Cell Biol 2: 589-598, 2001.

34. Carson JP, Kulik G and Weber MJ: Antiapoptotic signaling in LNCaP prostate cancer cells: A survival signaling pathway independent of phosphatidylinositol 3'-kinase and Akt/protein kinase B. Cancer Res 59: 1449-1453, 1999.

35. Lin J, Adam RM, Santiestevan E and Freeman MR: The phosphatidylinositol 3'-kinase pathway is a dominant growth factor-activated cell survival pathway in $\mathrm{LNCaP}$ human prostate carcinoma cells. Cancer Res 59: 2891-2897, 1999.

36. Beale PJ, Rogers P, Boxall F, Sharp SY and Kelland LR: BCL-2 family protein expression and platinum drug resistance in ovarian carcinoma. Br J Cancer 82: 436-440, 2000.

37. Moorehead RA and Singh G: Influence of the proto-oncogene c-fos on cisplatin sensitivity. Biochem Pharmacol 59: 337-345, 2000.

38. Shimizu S, Narita M and Tsujimoto Y: Bcl-2 family proteins regulate the release of apoptogenic cytochrome $c$ by the mitochondrial channel VDAC. Nature 399: 483-487, 1999.

39. Kagawa S, Pearson SA, Ji L, Xu K, McDonnell TJ, Swisher SG, Roth JA and Fang B: A binary adenoviral vector system for expressing high levels of the proapoptotic gene bax. Gene Ther 7: 75-79, 2000.

40. Rossé T, Olivier R, Monney L, Rager M, Conus S, Fellay I, Jansen B and Borner C: Bcl-2 prolongs cell survival after Bax-induced release of cytochrome $c$. Nature 391: 496-499, 1998.

41. Finucane DM, Bossy-Wetzel E, Waterhouse NJ, Cotter TG and Green DR: Bax-induced caspase activation and apoptosis via cytochrome $c$ release from mitochondria is inhibitable by Bcl-xL. J Biol Chem 274: 2225-2233, 1999.

42. Kitanaka C, Namiki T, Noguchi K, Mochizuki T, Kagaya S, Chi S, Hayashi A, Asai A, Tsujimoto Y and Kuchino Y: Caspase-dependent apoptosis of COS-7 cells induced by Bax overexpression: Differential effects of $\mathrm{Bcl}-2$ and $\mathrm{Bcl}-\mathrm{xL}$ on Bax-induced caspase activation and apoptosis. Oncogene 15: 1763-1772, 1997

43. Xiang J, Chao DT and Korsmeyer SJ: BAX-induced cell death may not require interleukin 1 beta-converting enzyme-like proteases. Proc Natl Acad Sci USA 93: 14559-14563, 1996.

44. Kagawa S, Gu J, Honda T, McDonnell TJ, Swisher SG, Roth JA and Fang B: Deficiency of caspase-3 in MCF7 cells blocks Bax-mediated nuclear fragmentation but not cell death. Clin Cancer Res 7: 1474-1480, 2001.

45. Sethi G, Ahn KS and Aggarwal BB: Targeting nuclear factor-kappa B activation pathway by thymoquinone: Role in suppression of antiapoptotic gene products and enhancement of apoptosis. Mol Cancer Res 6: 1059-1070, 2008.

46. Bellarosa D, Ciucci A, Bullo A, Nardelli F, Manzini S, Maggi CA and Goso C: Apoptotic events in a human ovarian cancer cell line exposed to anthracyclines. J Pharmacol Exp Ther 296: 276-283, 2001.

47. Keane MM,Ettenberg SA, Nau MM, Russell EK and Lipkowitz S: Chemotherapy augments TRAIL-induced apoptosis in breast cell lines. Cancer Res 59: 734-741, 1999.

48. Kottke TJ,Blajeski AL, Martins LM, Mesner PW Jr, Davidson NE, Earnshaw WC, Armstrong DK and Kaufmann SH: Comparison of paclitaxel-, 5-fluoro-2'-deoxyuridine-, and epidermal growth factor (EGF)-induced apoptosis. Evidence for EGF-induced anoikis. J Biol Chem 274: 15927-15936, 1999. 
49. Staudt LM: Oncogenic activation of NF-kappaB. Cold Spring Harb Perspect Biol 2: a000109, 2010.

50. DiDonato JA, Mercurio F and Karin M: NF- $\kappa \mathrm{B}$ and the link between inflammation and cancer. Immunol Rev 246: 379-400, 2012.

51. Longley DB, Harkin DP and Johnston PG: 5-fluorouracil: Mechanisms of action and clinical strategies. Nat Rev Cancer 3: 330-338, 2003

52. Calaf GM and Hei TK: Establishment of a radiation- and estrogeninduced breast cancer model. Carcinogenesis 21: 769-776, 2000.

53. Koh MS and Moon A: Activation of H-Ras and Rac1 correlates with epidermal growth factor-induced invasion in Hs578T and MDA-MB-231 breast carcinoma cells. Biochem Biophys Res Commun 406: 25-29, 2011.

54. Parri M and Chiarugi P: Rac and Rho GTPases in cancer cell motility control. Cell Commun Signal 8: 23, 2010.

55. Zhang B, Zhang Y and Shacter E: Caspase 3-mediated inactivation of rac GTPases promotes drug-induced apoptosis in human lymphoma cells. Mol Cell Biol 23: 5716-5725, 2003.

56. Osaki M, Tatebe S, Goto A, Hayashi $\mathrm{H}$, Oshimura $\mathrm{M}$ and Ito $\mathrm{H}$ : 5-Fluorouracil (5-FU) induced apoptosis in gastric cancer cell lines: Role of the p53 gene. Apoptosis 2: 221-226, 1997.

57. Violette S, Poulain L, Dussaulx E, Pepin D, Faussat AM, Chambaz J, Lacorte JM, Staedel C and Lesuffleur T: Resistance of colon cancer cells to long-term 5-fluorouracil exposure is correlated to the relative level of $\mathrm{Bcl}-2$ and $\mathrm{Bcl}-\mathrm{X}(\mathrm{L})$ in addition to Bax and p53 status. Int J Cancer 98: 498-504, 2002.

58. Lu Y, Zhang Z, Yan Z, Chen L, Deng W, Lotze M, Wang Z, Lin X and Li LY: Recombinant GnRH-p53 protein sensitizes breast cancer cells to 5-fluorouracil-induced apoptosis in vitro and in vivo. Apoptosis 18: 1214-1223, 2013.
59. Shen Y, Devgan G, Darnell JE Jr and Bromberg JF: Constitutively activated Stat 3 protects fibroblasts from serum withdrawal and UV-induced apoptosis and antagonizes the proapoptotic effects of activated Stat1. Proc Natl Acad Sci USA 98: 1543-1548, 2001.

60. Uetsuka H, Haisa M, Kimura M, Gunduz M, Kaneda Y, Ohkawa T, Takaoka M, Murata T, Nobuhisa T, Yamatsuji T, et al: Inhibition of inducible NF-kappaB activity reduces chemoresistance to 5-fluorouracil in human stomach cancer cell line. Exp Cell Res 289: 27-35, 2003.

61. Kodach LL, Bos CL, Durán N, Peppelenbosch MP, Ferreira CV and Hardwick JC: Violacein synergistically increases 5-fluorouracil cytotoxicity, induces apoptosis and inhibits Akt-mediated signal transduction in human colorectal cancer cells. Carcinogenesis 27: 508-516, 2006.

62. Wang W, McLeod HL and Cassidy J: Disulfiram-mediated inhibition of NF-kappaB activity enhances cytotoxicity of 5-fluorouracil in human colorectal cancer cell lines. Int J Cancer 104: 504-511, 2003

63. Wu H, Li W, Wang T, Shu Y and Liu P: Paeoniflorin suppress NF-kappaB activation through modulation of I kappaB alpha and enhances 5-fluorouracil-induced apoptosis in human gastric carcinoma cells. Biomed Pharmacother 62: 659-666, 2008.

64. Vinod BS, Antony J, Nair HH, Puliyappadamba VT, Saikia M, Narayanan SS, Bevin A and Anto RJ: Mechanistic evaluation of the signaling events regulating curcumin-mediated chemosensitization of breast cancer cells to 5-fluorouracil. Cell Death Dis 4: e505, 2013. 